$J H A$, xxii (1991)

\title{
THE KENYA EXPEDITIONS OF LEIDEN OBSERVATORY
}

\author{
J. K. KATGERT-MERKELIJN, Leiden Observatory
}

\section{INTRODUCTION}

Twice in the present century Leiden Observatory equipped and sent out an expedition to make astrometrical observations from a place as near to the equator as possible. These expeditions constitute an unusual chapter in the history of the Leiden Observatory and, at considerable cost and effort, yielded results that can be shown to have been unduly neglected.

With the inventarization of the papers of $\mathbf{J}$. H. Oort an important source of material has become available, as Oort was involved in almost all aspects of the expeditions. In this article we attempt to tell the story of the Leiden expeditions to Kenya: their background, organization, goals, course, and results.

\section{A NEW METHOD OF DETERMINING ABSOLUTE DECLINATIONS}

\section{An Amateur Astronomer in the Congo}

At the end of the last century J. C. Kapteyn published a proposal ${ }^{1}$ for a method to determine absolute geographic latitudes, the essential first step towards determining the accurate stellar positions needed for both navigation and astronomy. Some thirty years later, C. Sanders realized that the method could be adapted to determine fundamental declinations from sites on, or near to, the equator. Sanders had been an agent for an English coffee company at Chiloango in the Portuguese Congo (in what is now Zaïre, at a latitude of approximately $-5^{\circ}$ ); from 1910 onwards he owned a plantation at nearby Cabinda. He was a man who took a lively interest in astronomy and spent a considerable amount of time and money on it: on handbooks, telescopes, clocks, catalogues, and any observations he could get in spite of the wet climate in the Congo (he bought a universal instrument for 4000 marks, a very large sum of money in those days). He also spent considerable time and effort in establishing the coordinates of places in the Congo where he stayed for any length of time. Thus he was able to correct the first rough survey of the surrounding area; he also determined the course of the Chiloango river. In 1904 he reported on his results to the King of Portugal; and he was made a knight of the Order of São Chiago.

From December 1892 onwards Sanders also made a practice of reporting his results to E. F. van de Sande Bakhuyzen (Professor of Astronomy and, later, interim director of Leiden Observatory); the latter would then report them to the Royal Netherlands Academy of Sciences. 
The First World War had some surprising side-effects. To quote from a letter from Sanders: 2

I am hampered by the lack of ephemerides, the Nautical Almanac for its current year not being in my possession. Instead of the complete edition, I got, from Lisbon, the abridged one, for the use of sailors, which is almost useless for my purposes.

In order to compensate for the lack of ephemerides I calculated the "quantities for correcting the places of stars" for Greenwich midnight. ... With these "quantities" I may now calculate the apparent places of stars as required. The work involved, however, is rather considerable, and I, therefore, investigated a method of obtaining the latitude of the place of observation and the declinations of stars without the help of ephemerides. As this method does not seem to be mentioned anywhere, perhaps on account of its unimportance for practical purposes, I take the liberty of communicating the idea. Hoping that you will favour me with your views on the subject.

Newcomb contends, in his "Compendium of Spherical Astronomy" that no fundamental determinations of declination can be made except in the way he explains, viz. by determining the circle reading corresponding to the direction of the pole and by subtracting this reading from the readings of stars at their culmination, thus obtaining their polar distances.

When we approach the equator this method becomes useless owing to the small elevation of the pole. One infers, therefore, that no absolute determinations of declinations can be made in low latitudes. This is evidently incorrect, at least theoretically.

If, instead of measuring polar distances we observe, with a good size altazimuth, solidly mounted on a pier, the angle between the extreme positions, east and west of the meridian, of circumpolar stars, we obtain both the direction of the meridian line and the azimuth of digression or elongation. As all stars culminating between the elevated pole and the zenith reach an observable maximum azimuth, given by the formula $\sin A=\cos \delta / \cos \varphi$ [where $\varphi$ is the latitude], the number of stars observable in this way increases from the pole to the equator. If we now measure also the meridian zenith distances of the same stars we have all that is required to calculate the latitude of the place of observations and the declinations of the observed stars.

Sanders anxiously waited for the comments of Van de Sande Bakhuyzen. However, again because of the war, he was to get no reaction to his letters for about a year; after half-a-year's wait he therefore wrote a letter ${ }^{3}$ to the journal The observatory, explaining his method. The editors of The observatory commented: 4

The method would appear to be capable of yielding results of considerable accuracy, provided that sufficient precautions are taken to ensure the stability of the telescope. The principal disadvantages are that the observing must necessarily be very slow, and that many observations are 
likely to be lost owing to complete sets not being obtained. The method is not recommended for field-astronomy in preference to the methods usually adopted.

Sanders did not let himself be discouraged; he continued his observations, and resumed his contacts with Leiden Observatory, where W. de Sitter had become Director in 1918. De Sitter is quoted as saying that each observing technique has its own systematic errors, hence the mean of the results of different techniques is the best one can get. One consequence of this attitude was that he saw better possibilities in Sanders's method than had The observatory, and he set about doing something about it.

\section{The Determination of Fundamental Declinations}

In the nineteenth century considerable ingenuity had been spent on improving the accuracy of stellar positions. By 1920 various reliable catalogues were available, particularly for the northern sky. However, the positions had mostly been obtained using meridian instruments, which were able to yield very accurate right ascensions, but relatively uncertain declinations. Individual telescopes provided consistent and seemingly accurate declinations, but there could be fairly large differences - up to a second of arc and more - from telescope to telescope. It was assumed that these differences were due to flexure of the telescope and to refraction. For both effects it was practically impossible to determine corrections. For the problems being addressed by the 1920s, an error as large as one second of arc was quite unacceptable; this was especially true for the stellar statisticians, who were wholly dependent on the efforts of the astrometrists to provide the accurate parallaxes, statistical parallaxes and proper motions needed for the study of the dynamics of the Galaxy. As Leiden Observatory was becoming deeply involved in investigations of stellar dynamics and galactic structure, it was not surprising that De Sitter should think Sanders's method merited further consideration.

Sanders's idea can be summarized as follows. An observing site should be selected as close as possible to the equator. On the equator the azimuth of any given star at rising or setting is exactly equal to its declination. Therefore, while at higher latitudes declinations are normally determined by measuring zenith distances in the meridian, in this method azimuths would be measured as near as possible to the horizon, and preferably at the same elevation at both rising and setting. In this way, errors due to telescope flexure and vertical refraction are eliminated, and errors in right ascension and in time do not affect the observations. At sites not exactly on the equator but within a few degrees of it, or if the observations are done at non-zero elevations, the errors in right ascension and in time enter the equations with very small weight $(\approx 0.1$ as compared with 1 for meridian observations), as there is a $\sin \varphi$ factor in the equations, where $\varphi$ is the latitude. Normally one will be able to observe the program stars both at rising and at setting only by allowing intervals of some months between the observations, but the method works equally well if one 


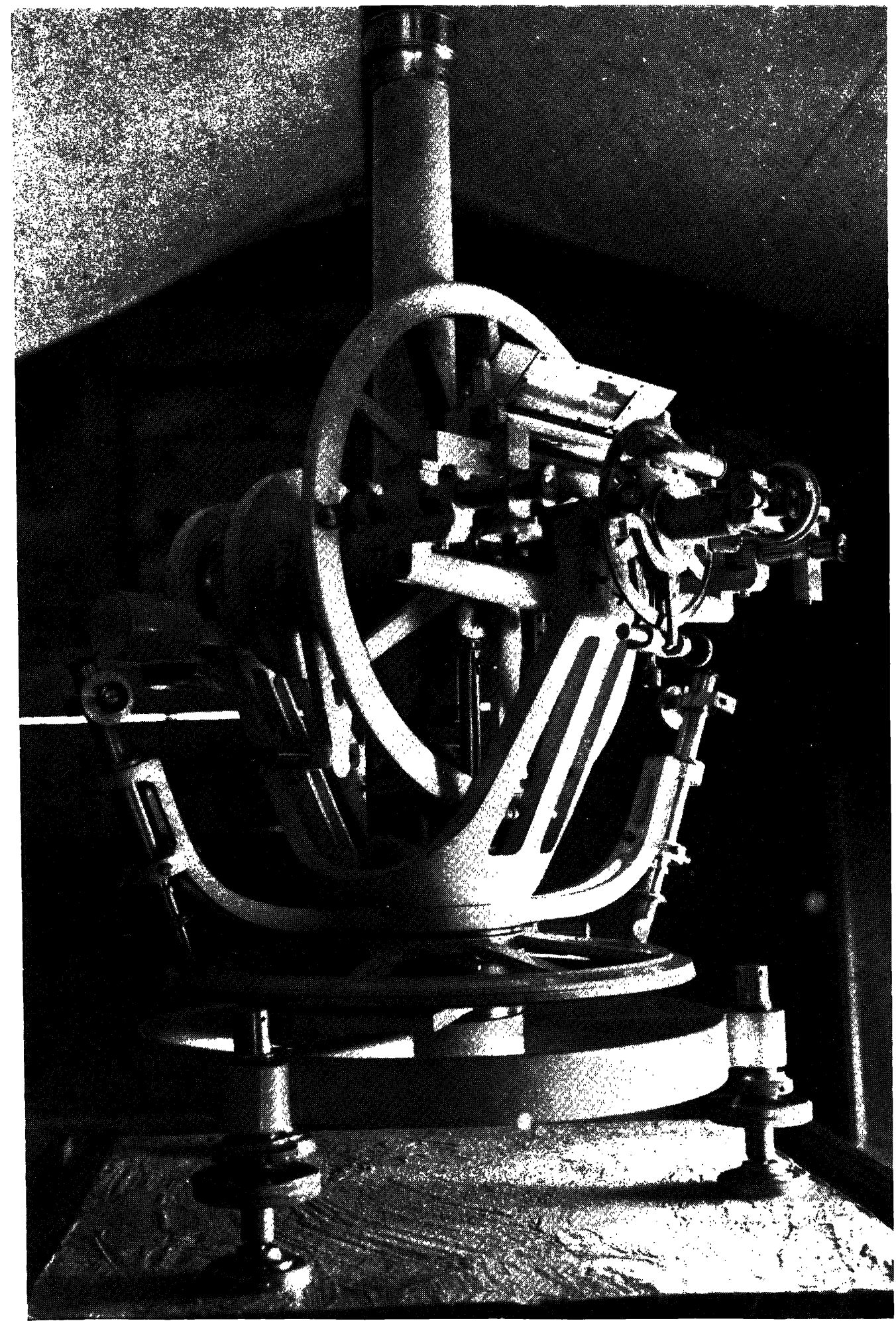

FIG. 1. The Universal Instrument by Sartorius used by C. Sanders. Photograph from S20.17. 
observes a cycle of stars, in narrow strips of declinations symmetric to the equator and evenly distributed in right ascension; then under certain conditions the errors will cancel when the observations are combined.

The experiences of the two Leiden expeditions have shown that it is not quite as straightforward as it sounds, but De Sitter certainly thought the method sounded promising, and asked J. H. Oort, who had just joined the staff of Leiden Observatory (in 1924), to investigate the possibilities further. As a result of Oort's involvement two papers were published, one (De Sitter and Oort ${ }^{5}$ ) being a further definition and elaboration of the method to be used, the other (Sanders and Oort ${ }^{6}$ ) a summary of first results of the method as applied by Sanders in Cabinda.

\section{First Results}

Sanders had started his own plantation at Cabinda in 1910, but in 1922 the enterprise failed, leaving him practically destitute. He just managed to keep body and soul together by doing some surveying for the Portuguese government. Sanders's plantation was sold; he was left with the house and the small observatory he had built next to it. He had given title to the instruments to Leiden Observatory some years before, keeping their use, and so they were exempt from the bankruptcy proceedings. In these circumstances, De Sitter managed to find funds to pay Sanders a small annuity for some years, with the proviso that in return he should carry out observations for Leiden Observatory to test his method for obtaining fundamental declinations.

The results looked extremely promising. Considering that the telescope used (a Universal Instrument by Sartorius, Figure 1), though an astrometric instrument, had not been specially designed for these observations, the results were internally quite consistent. It seemed feasible to solve for personal error and instrumental effects, even though some hard-to-explain discrepancies remained between observations at extreme hour angles. The conclusion was that the method was suitable to give some idea of the systematic corrections to be applied to the various declination zones.

De Sitter decided that an attempt should be made to find money for a project to determine systematic corrections per declination zone accurate to 0.05 to the catalogues of fundamental positions then available (L. Boss's Preliminary General Catalogue, and the Fundamental Catalog). He put in an application to the International Astronomical Union, which granted $£ 750$ for the construction of an azimuth instrument; De Sitter also carried out a campaign for funding an expedition to a site as near as possible to the equator in order to test the method more thoroughly than had been possible with Sanders's telescope. In its original form, the idea was that fundamental declinations should ultimately be determined by matching observations on the equator and at intermediate latitudes both north and south, but this plan never materialized.

Construction of the azimuth instrument that De Sitter had in mind proved unexpectedly expensive. A German firm quoted 19,000 marks, another quoted 7500 marks, and a British firm quoted £640; this last offer was accepted. 
However, when the instrument was delivered (around 1929) there proved to be considerable inaccuracies (e.g. in the circles), and it was not until 1931 that De Sitter considered the instrument to fulfil the specifications and to be ready for use.

By that time sufficient funding had been obtained to equip an expedition. The Dutch government made a grant of $£ 1000$, and various science funds made smaller contributions. Private individuals also gave generously, in one case a contribution of $f 3000$.

The question of the exact observing site for the expedition remained. There are not many places on Earth both sufficiently near the equator and at the same time suitable for astronomical observations. Three possibilities were considered: the Padang Highlands in Sumatra at an altitude of about $750 \mathrm{~m}$ (for which enough information was available to show that the climate was unsuitable); Quito, Ecuador; and Kenya, both at altitudes of over $2000 \mathrm{~m}$. At first sight Quito looked promising: there was known to be an observatory there, giving hopes of the availability of living quarters, water, electricity, transport, and technical support, and the town itself is at an altitude of $2000 \mathrm{~m}$. So, in June 1929 , De Sitter wrote a hopeful and somewhat gushing letter to "The director of the Observatory" there:

The Observatory of Quito is privileged over all other observatories in the world on account of its situation in a very high altitude and exactly under the equator. These two exceptional conditions make Quito the one spot on the earth for the principal station (of the azimuth expedition). ... I am therefore writing to you to ask ... also if you could give us some information regarding the climate of Quito, especially as to cloudiness, and astronomical seeing. ${ }^{7}$

He never got a reply. However, he did manage to obtain some information from a former director, ${ }^{8}$ who was able to tell him that, in fact, the climate was poor, with a pronounced wet season of some months during which observing would be practically impossible, and that furthermore the high mountains surrounding Quito would make the determination of azimuths at low elevations impossible over much of the horizon. As one requirement for the site was a certain number of good nights in all seasons, because of the cyclical nature of the planned observations, and another a free horizon, Quito was effectively ruled out.

This left Kenya, a country where a large area near the equator reaches considerable altitudes. Inquiries made at the Colonial Office in London produced enthusiastic reactions: a $\mathrm{Mr} \mathrm{A}$. Walter, former astronomer and now meteorologist in Kenya, thought ${ }^{9}$ the climate should be very suitable and promised help and support. Accordingly, two astronomers, C. H. Hins, Conservator at Leiden Observatory and chief of the Meridian Department, then aged 41, and G. van Herk, Assistant at the Observatory, then aged 23, embarked for Kenya in July 1931, accompanied by 25 crates of instrumentation. They travelled by Holland-Africa Line, which considered itself directly interested in a project that would also be of aid to navigation, and therefore carried the crates free of charge and the astronomers at half-price. 


\section{THE FIRST KENYA EXPEDITION}

\section{Site Selection and Setting Up}

The main railway line going inland from Nairobi crossed the equator then (and still does) in three places, two of which at first sight seemed to be suitable sites. One was near a small township, Nanyuki, which offered the advantage of a good infrastructure. A drawback of this site, however, was that Mt Kenya blocked a large wedge of the horizon. There was no such drawback to Equator, at another crossing; here the climate also seemed marginally better, especially at night. (Van Herk went to Nanyuki for a week, and Hins to Equator, to test observing conditions.) Circumstances at Equator were rather more primitive, but the nearby farmers offered help and accommodation, and Equator was selected. The astronomers were to live with the Carver family on Canada Farm; the observing station was to be erected on Crown land nearby, on the top of a slight rise.

The farm where they were to lodge for the next one-and-a-half years is described by Hins: "The size of the farm is 1000 hectares [about 2500 acres]; it has cattle and agriculture, jungle with animals and apes, hills and valleys. In short, it is a small empire in itself."10 In due time the crates containing the instruments and other equipment arrived at Equator and were brought to Canada Farm by cart, drawn by twelve oxen; this was the only possible way to get the heavy equipment up the road. A big army tent had been brought along and was set up first, in order to shelter the crates from sun and rain during the construction of an observatory hut. Building materials also arrived by ox cart: the ingredients for pouring concrete for the foundation for the azimuth instrument and for the zenith telescope Van Herk was to work with, and large quantities of other building materials including wood, rail, celotex (roofing material) and bitumen. From this material, in the course of the next two months, a sturdy little hut was built that would shelter the telescopes, registrators, clocks, etc., during the daytime, keeping the temperature constant to within very narrow limits - of special importance for the optical parts and the clock - and would fold out at night to allow an unimpeded view in all directions (Figure 2). Great care was taken that the hut was anchored independently of the telescope foundations (to the surprise of the local workmen, who had assumed that the concrete foundation would make a good solid base for the hut).

Most of the materials for the observing station arrived in good order, though sharp protests were made against the high freight rates charged by the railways; in particular the transport of the material brought from the Netherlands (the telescopes and everything to go with them) was very much more expensive than expected. In their protest the astronomers called it unfair that of a grant made by an international scientific body (referring to the $£ 750$ from the IAU) fully half should go to swell the treasury of the Kenya Railway Company. A rebate was applied for, but Hins was successful only in getting a reduction for the return journey. At least the instruments arrived at the site without serious 

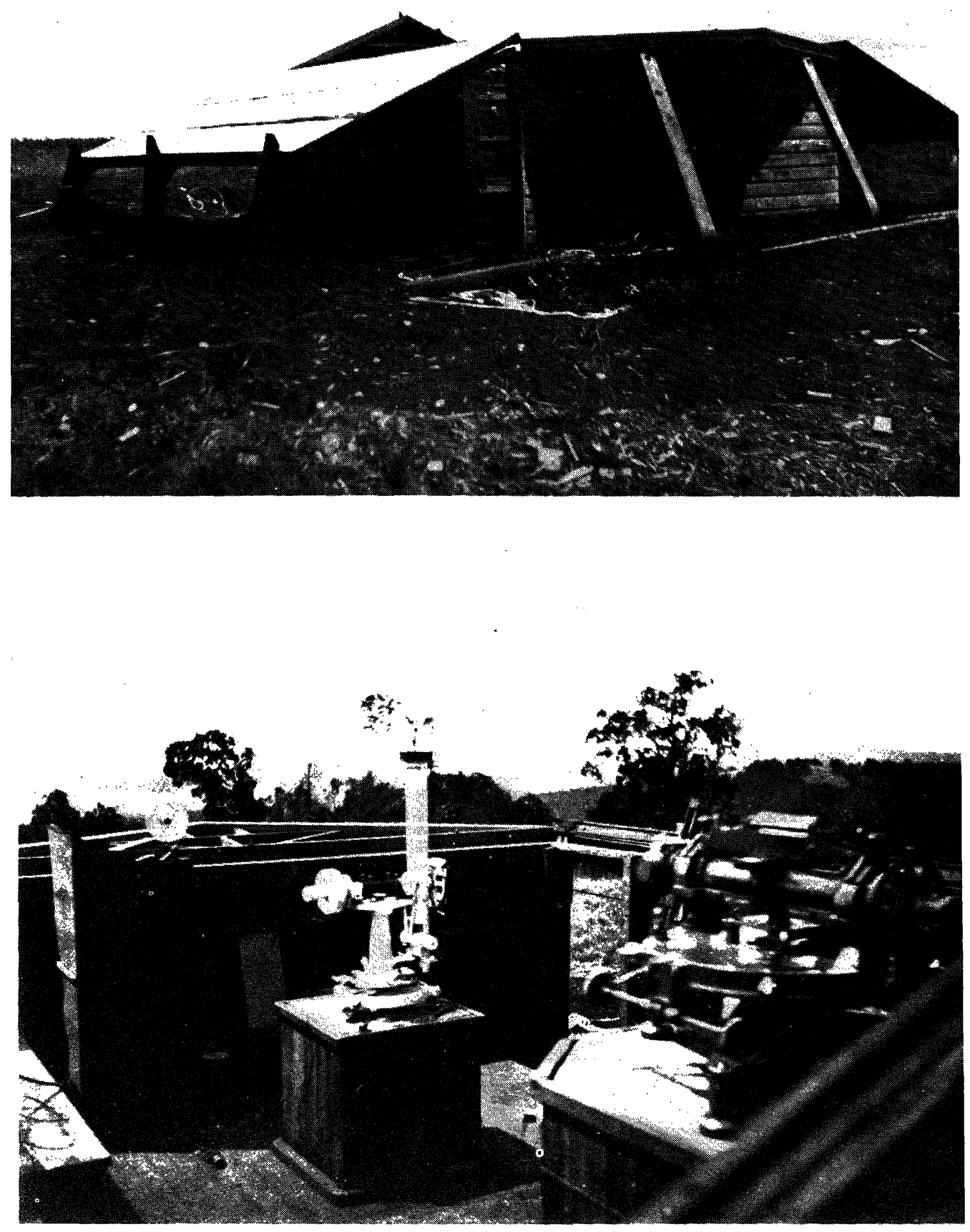

FIG. 2. Observing hut for the first expedition, with azimuth instrument. During the day the front and back would fold in and the roof would slide shut on rollers. (a, above) As seen from outside, (b, below) as seen from inside. Reproduced from Hins and van Herk, op. cit. (ref. 24). 
damage. This was, however, not always the case for the other materials. From Hins's diary:

Oct. 22. Sulfuric acid, 1100 bricks, sheet iron, celotex have arrived. The first item is transported to the farm with the utmost care, and stored in the tent. We want to begin filling up [the batteries]. Inscription on cases: "Not to turn!" "This side up!" We open the first crate and: the three jars are all upside down, two are empty and one is half full. Sawdust burned; that could have caused a railway fire."

\section{The Observations}

Observing started on 15 November 1931, some two months after the arrival of the expedition at the site. The first observations showed the necessity of redetermining the latitude:

Our site was right on a triangulation point of the map and as it was easy to read off in $\mathrm{mm}$. and the equator had been drawn in officially, our latitude should be $-0^{\circ} 0^{\prime} 28^{\prime \prime} \ldots$ to our great surprise the observations at Zenith Distance $45^{\circ} \mathrm{W}$ gave a North Pole 12 to $13^{\prime \prime}$ higher, those at $45^{\circ} \mathrm{E}$ a N.P. 12 to $13^{\prime \prime}$ lower than the night's mean ... we immediately installed the Zenith Telescope, and sure enough, Van Herk found a preliminary value for the latitude of $-0^{\circ} 0^{\prime} 42$ or $43^{\prime \prime}$. Both the survey map and the large published map would be off by $15^{\prime \prime}$, i.e. the equator is $450 \mathrm{~m}$ further to the north. ${ }^{12}$

In the first reduction of the actual observations there were signs that there might be some quite serious problems, partly due to the instruments, partly due to the circumstances under which the observations had to be made. ${ }^{13}$ To quote from a letter from Hins:

The mirror behaves oddly and, without making any definitive statements now, I very much fear that small movements of the mirror, even though incidental, will influence the mean error in the results in such a way that the good points of the method will be lost in part. ${ }^{14}$

And, in the same letter:

Linking evening and morning observations is practically out of the question. I won't blame the weather exclusively, although we can do so for $75 \%$. We cannot do it. Maybe it is the thin air, maybe it is the difference between the heat in the daytime and the night temperature, or the difference in humidity, but neither I (who can take quite a bit) nor Van Herk, who has become much stronger here, can work from six to six. Now if you are at a permanent observatory, with heated offices and some comforts, then it would be possible, but not here on the hill top, where 
when it is clear there is always an icy wind. But fortunately this reason is secondary. The main reason is that nights that are clear from sundown to sunup hardly seem to occur at all.

By the time this letter was written it was already clear that there were sudden jumps in the system that could be expected to affect the reliability of the results. To show how these occurred it is necessary to describe briefly the method of observation.

A complete observation comprised: pointing the instrument to one star of an east-west pair, bisecting the star with a moveable crosswire, reading off the values of the circle and the level, determining the point of intersection of the moveable and the fixed crosswire, reversing the telescope, and repeating the procedure in the second orientation (with the aim of eliminating collimation errors). Then the entire procedure had to be repeated for the second star of the pair. Two sets of stars were observed, namely, the cycle stars observed for a determination of the zero point of the horizontal circle $\left(24\right.$ stars within $2^{\circ}$ of the celestial equator, each star of a pair being observed at a zenith distance of $45^{\circ}$ ), and the stars observed for the determination of the corrections to the fundamental declinations. As to these latter stars, the goal was to have observations for one star for each hour of right ascension and $5^{\circ}$ of declination between declinations $-50^{\circ}$ and $+50^{\circ}$. To determine changes in the zero point of the instrument with as great an accuracy as possible, the azimuth of a permanent earth-bound mark was also observed at regular intervals of time. For this purpose a so-called azimuth mire, consisting of a light bulb with lens on top of a concrete pillar, had been built at a distance of about $250 \mathrm{~m}$; as the telescope was on the top of a hill, it had to be aimed slightly below the horizon to observe this mark. The azimuth mire was observed at least at the beginning and end of each night's observations; the results, i.e. the azimuth of the mark, should have been the same within the measuring error; but it was soon found that there were large differences between the individual readings, indicating a change in the collimation constant of the telescope during the course of the night, or possibly a movement in the pillar.

In the course of the expedition, everything the expedition members as well as the Leiden Observatory staff could think of was tried to pinpoint the error. De Sitter recalled ${ }^{15}$ a comment from Benjamin Boss: "You are going to discover a whole new set of systematic errors." One British astronomer when asked for advice said: "You go over the whole instrument and try out all the screws until you find the one that has been loosened by the transport and the temperature changes and tighten it." ${ }^{15}$ But nothing of the kind was found. The azimuth mire was taken down and rebuilt, somewhat nearer in so that its distance was as close as possible to the focal length of the instrument when fitted with the additional objective needed to measure the mire; but that made no difference. A shield was built so that there would be no chance of the astronomer himself heating up the telescope while reading off the circle; this seemed to give some improvement but Hins and Van Herk remained strongly suspicious of the strong, icy winds that always blew when it was clear, and always from the same quarter, affecting east 
and west observations in different ways. Various observations were tried to find workable corrections and these did seem to give some positive results.

But the isolation of the expedition site and the lack of technical support made it difficult to solve all the problems. The presence of a mechanical workshop might have made some difference; as it was, some words written by Sanders in 1918 apply here also: “... I am here like Robinson Crusoe on a desert island, insofar as Scientific advice is concerned, and I have consequently to work out my own salvation and to rectify my own mistakes." 17 Hins used the same simile, although in another context, in a letter written early in May 1932:

I don't want to leave a South Seas Island with four inhabitants just to establish myself for a few days on another island with six inhabitants. I need to combine [trips away from the site] with a race meeting where I speak to people not about Astronomy and Meteorology but about horses and dancing etc. ${ }^{18}$

The circumstances of the observing were found to be such that regular days off were necessary. Relations with their host, a Mr Carver, were reasonable, but trying to sleep in the day-time on a farm is not easy. Hins mentions some of their nearest neighbours, a farmer and his wife living some eight miles off, as good friends; there were trips to Equator, to Eldoret and, occasionally, to Nairobi, to relieve the monotony of the observing task. Otherwise it was hard work. The astronomers would work in tandem, one making the readings while the other wrote them down, for as long as the sky remained clear; during the daytime there would be preliminary reductions to do and observing schedules to draw up for the coming night. Hins gave a vivid description of the observing: ${ }^{19}$

Those were curious observing nights we had this week: I can hardly call it observing, it is rather fighting the elements. At 7 o'clock generally a downpour, at 8 it is clearing up, but in such a way that the difference between the wet and the dry sphere of our hygrometer is $0^{\circ} .1$, meaning a dew soaking everything. Then an icy north-easterly wind rises, bonechilling even though the thermometer does not fall very low, 7 or $8^{\circ} \mathrm{C} .^{20}$ The writer, $2 \mathrm{~m}$ away from the observer, can hardly hear the latter. In this way it remains clear for a few hours. The floor is so wet that you have to watch your step in order not to slip; before each setting of the micrometer or reading of microscope and level you have to rub everything dry; the dew-cap has to be removed to clean the objective a couple of times. Writing pad, observing lists, paper tape are all so soggy that the pencil hardly makes an impression. Then, at around midnight, sometimes earlier sometimes later, the upper atmosphere wins (I don't know enough of meteorology to put it better) and suddenly the sky is overcast; no time for the final pair of $45^{\circ}$ stars. Just as well we at least have the mire. Is this observing or fighting?

When the tape is so soggy, we can't roll it up so we leave it in the paper tray until morning. The other day Van Herk found the tape heavily 


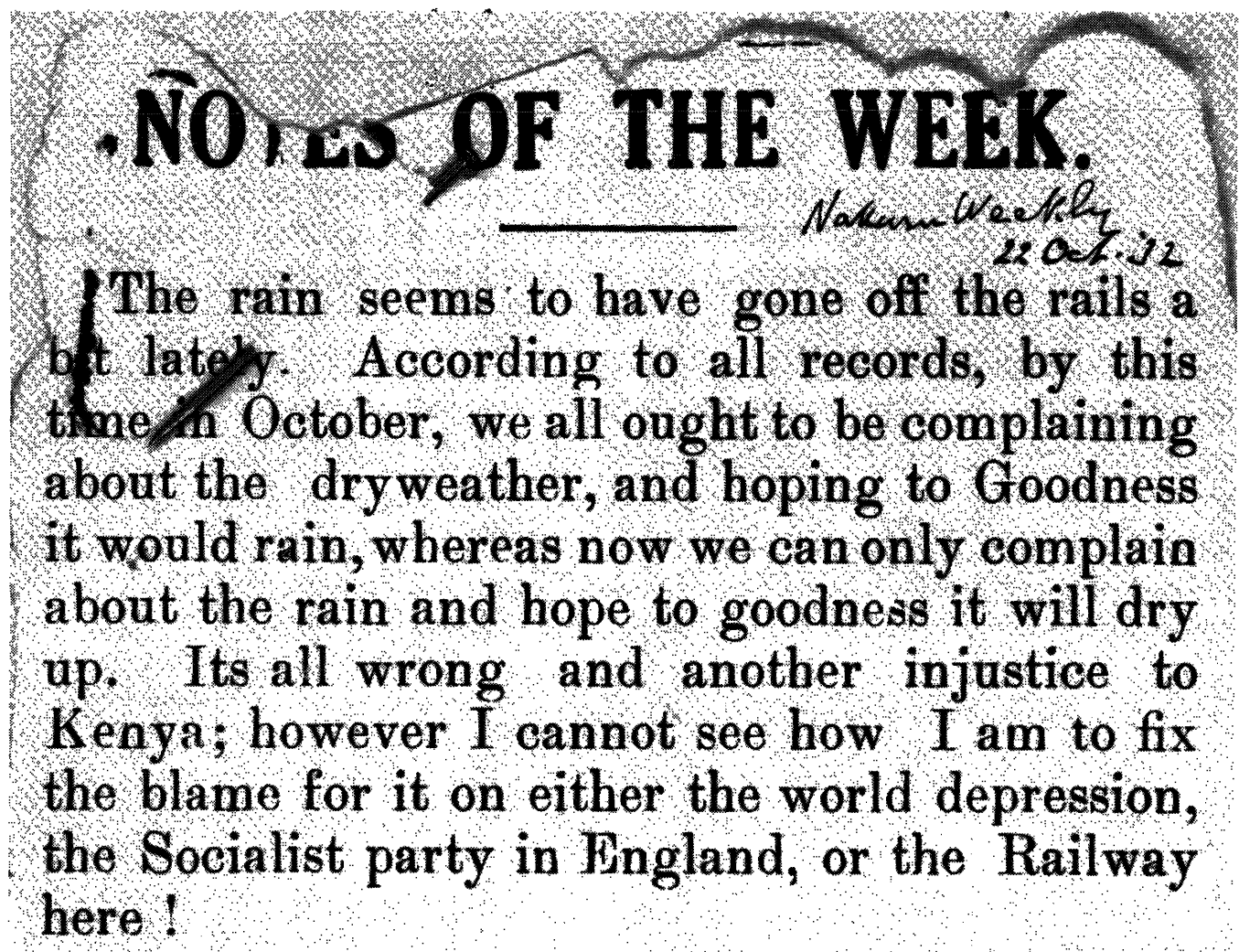

FIG. 3. Newspaper cutting on the weather in Kenya during the first expedition. From O3.7.1931(a).

damaged because a mouse had got into the tray and by fitting and glueing we had to reconstruct it.

That same night, on my way to the "Observatory" a large adult leopard jumped before the car and sat less than $10 \mathrm{~m}$ away from it, dazzled by the lights. Too bad I did not have a gun with me; now he jumped back into the dark on the side of the road. It was a scary idea that night, having that character roaming around so close. They are said never to attack as long as you don't do anything to them, nevertheless, you never can tell. ${ }^{21}$

Other than the unexpected shifts in the collimation constant, the weather was the greatest problem and probably did most to affect the quality of the results, as not all observations of the cycles could be obtained. The weather was exceptionally bad in 1932; in September, when usually it would clear up, it remained wet and overcast that year; at one stage Hins sent a newspaper cutting (Figure 3) to show that he was not the only one complaining and that the weather was, indeed, unusually bad. Late in 1932 they had grave doubts about meeting the goal of the expedition, and Hins suggested to De Sitter they should carry on for two more months (the expedition was supposed to return home in April 1933). De Sitter pointed out that, as April and May were usually wet, too, there was not much point in remaining. Fortunately January and February 
gave an unexpected run of good weather and they achieved a reasonably complete set of observations.

\section{Results and Conclusions}

During the last half-year of the Kenya expedition Hins sent regular statistics of the observations obtained so far; they clearly show the improvement in the weather. The code is as follows:

I. East two or more, west two or more observations.

II. East two or more, west one or vice versa.

III. East one, west one.

IV. East two or more, west none or vice versa.

V. East one, west none or vice versa.

VI. Not observed.

The numbers of observations given are cumulative numbers.

19321933

Date: 20 Oct. 27 Oct. 3 Nov. 1 Dec. 4 Jan. 30 Jan. 20 Feb. 23 Mar. Code

$\begin{array}{lrrrrrrrr}\text { I } & 63 & 67 & 79 & 79 & 96 & 98 & 105 & 121 \\ \text { II } & 104 & 111 & 124 & 124 & 151 & 161 & 214 & 218 \\ \text { III } & 16 & 16 & 13 & 13 & 9 & 8 & 4 & 3 \\ \text { IV } & 100 & 100 & 90 & 90 & 151 & 171 & 139 & 122 \\ \text { V } & 4 & 62 & 60 & 60 & 33 & 27 & 4 & 2 \\ \text { VI } & 152 & 127 & 117 & 111 & 45 & 20 & 19 & 19\end{array}$

The decision to break up the expedition was taken; the results would be worked out completely in Leiden. Hins tried his hardest to find a good destination for the material that could not be shipped back to the Netherlands, such as the car, batteries (for the electricity needed for the observations) and, particularly, the observatory hut. It was a sturdy building (Hins, when it was built, commented: "I repeated what I have told myself so often: you can't build something that will last 18 months exactly"22), and it seemed a pity to leave it to the mercy of the elements. Quite early in the expedition enquiries had already been made of the meteorological office, for whom the hut seemed quite suitable. They were interested in principle, but short of money, and kept referring the question back to the Colonial Office in London. When pressed for a commitment, Walter (the meteorologist in Kenya) in January 1933 “... wrote me a very vague, evasive letter, in which of all things he asked me for some sort of guarantee of the climate and weather here. I couldn't repress a smile when I read this; after all we came to Kenya because of his strong recommendation of the climate." 23

In the end the building was sold to the Meteorology Department under the proviso that payment would not be made until the next financial year at the earliest. From the correspondence for the second Kenya expedition it does in fact appear that the transfer was made and that a meteorological station was set up, using the building of the first expedition.

The members of the expedition were finally able to return to Leiden. Van 
Herk left for Europe on 11 April. Hins intended to go on safari before selling the car, but was stranded at the start of his trip because the garage had forgotten to put in new oil. He successfully threatened the garage with a law-suit if they would not take the car off his hands at a fair price, and embarked for Genoa on 29 April 1933.

The results of the first Leiden expedition to Kenya are published in the Annals of Leiden Observatory. ${ }^{24}$ The results were somewhat disappointing in that they did not achieve the goal of a correction accurate to 0." 05 , even though De Sitter insisted that the expedition had done as well as might have been expected, and that, after all, it had an exploratory character. The main conclusions were that the method worked in principle, but that a duration of eighteen months was insufficient, as such a period did not guarantee a sufficient sky coverage. In addition the stability requirements for the azimuth instrument were even more stringent than had been expected. There was a suspicion that the objective glass had shifted somewhat at each reversal of the instrument. Part of the discrepancies in the results was ascribed to the climate, in the sense that the constancy of the wind direction affected the observations in a way that depended on the orientation of the instrument. In fact a technical investigation some years later in the workshop of Leiden Observatory showed that the discrepancies could in large measure be ascribed to hysteresis: in reversing the telescope the direction in which the reversal was made proved to make a difference in the circle reading of up to $1^{\prime \prime}$.

\section{THE SECOND KENYA EXPEDITION}

\section{Preparations}

By the time the definitive results of the first expedition were available the situation in Leiden had changed considerably. De Sitter had died, very unexpectedly, of pneumonia, in 1934. He had been succeeded as Director by Ejnar Hertzsprung, who was not particularly concerned with astrometric observations. However, Oort remained interested, and felt strongly that the experience acquired with the first expedition should not be lost.

The first step toward a second expedition had to be to acquire the necessary funding. A successful application was made to the IAU; but then the Second World War intervened, so that it seemed that all thoughts of a second Kenya expedition would have to be suspended for the time being. It seemed so; but actually some further fundraising was done, successfully in the case of the Pieter Langenhuizen Lambertuszoonfonds (PLL Fund), which in 1943 honoured an application for $f 4500$, to be used when convenient. The application was specified as follows: ${ }^{25}$ travel costs (to Sumatra!), $f 2000$; extra cost-of-living supplement for one observer, $f 2500$. Considering that the first expedition had cost some $f 20,000$, these figures were clearly over-optimistic, if not completely unrealistic; in fact the grant was seen as a first step towards the goal.

Once Oort had succeeded Hertzsprung as Director of the Observatory in 


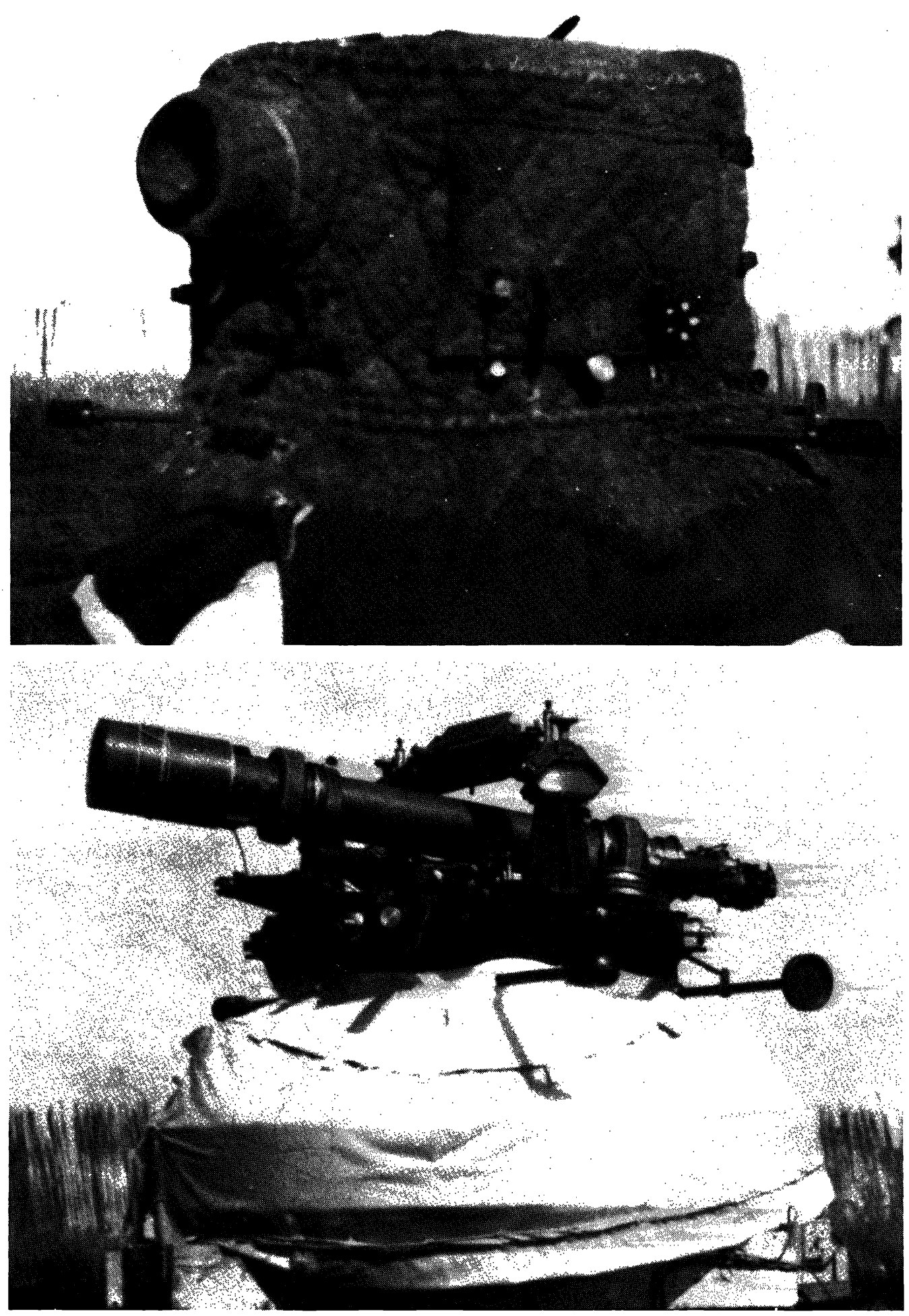

Fig. 4. The azimuth instrument as used during the second expedition, (a, above) with insulating cover, (b, below) without cover. Photograph (a) by W. van Zadelhoff, (b) courtesy of A. Blaauw. 
1945, the second step involved the refurbishing of the instrument. The original instrument was retained, but considerable structural changes were made. The possibility of reversing the instrument was abandoned. On the advice of the French astronomer A. Danjon the manœuvrability in elevation was also abandoned; the elevation of the tube was fixed at $9^{\circ}$ (i.e. a zenith angle of $81^{\circ}$ ), which meant sacrificing the observations of cycle stars at Zenith Angle $45^{\circ}$ and the determination of the collimation constant. Then the whole instrument was insulated as thoroughly as was compatible with allowing light to enter the objective, so that it ended up looking "like an Eskimo during a Polar winter" (Van Zadelhoff) (Figure 4). In practice, this cover was found to hamper the observations so severely that it was abandoned and replaced by a skirt around the support of the instrument. Lastly, the readings were automated; the circle settings would be photographed, and the film records sent back to Leiden to be measured there.

Almost as soon as the war was over, Oort, together with J. van der Bilt, Reader in Astronomy at Utrecht University, proceeded to organize the expedition. It was a difficult time for fund-raising. Some institutions and some special funds allocated money, but the private persons who had contributed substantially to the first expedition mostly excused themselves, on the grounds that tax structures now were such that they could no longer "allow themselves the pleasure of contributing", and felt that now it was the government who should do so. Although some private individuals contributed to the expedition, the government, mostly by way of what was to become the Netherlands Organization for Pure Research, in fact did meet more than half of the total costs of the expedition.

The Holland-Africa Line, which had contributed substantially to the first expedition by offering free or reduced transport charges, now felt that the improved availability of good standards for navigation did not justify their support of an expedition to determine fundamental declinations. Nevertheless, they felt some involvement and decided to contribute to the funds. At the end of the fund-raising effort, Oort felt sufficiently secure to proceed with the expedition.

The possibility of trying another site instead of Kenya had been raised during the war: in the application to the PLL Fund the Padang highlands of Sumatra were mentioned as the probable destination. However, further investigations of the climate there indicated that it was certainly not better than Kenya for astronomical observations, but was possibly worse, and even more isolated. It did not occur to anyone at this stage to give Ecuador another try. So it was decided that the expedition should again go to Kenya, to a site a few kilometres from the site of the 1931 expedition, within reach of the Equator railway station, and in theory within an easy drive of Eldoret, the nearest sizeable town.

Next came the problem of equipping the second expedition. This was a serious problem, as the expedition had to be practically self-sufficient. In these years just after the war normal equipment was still scarce in the Netherlands, and imports were difficult because of currency regulations. The expedition members had to bring to Kenya their own electricity supply, in the form of 
batteries and a generator, and most of the equipment they might need; at least this was the ideal, although in practice they were short of everything and improvization was the order of the day. It also was felt desirable to bring a truck as in Kenya these were in short supply and generally, if second-hand, in bad shape. Even the possibility of taking prefabricated houses was considered, but in the end it was thought to be cheaper to have these constructed locally.

These houses were necessary because it had been decided that this time the expedition members would bring their families, in view of the estimated duration of at least three years. Van Herk, having been a member of the first expedition, was the obvious choice for leading this one. The second member of the expedition was Lt 1st class W. van Zadelhoff, on secondment from the Dutch Navy. P. de Haan, the Observatory Carpenter, was to go along for the first six months, to help in the construction of the observatory huts, etc.

Van Zadelhoff was a relative of Marcel Minnaert (then Professor of Astronomy at Utrecht University). When he heard of the expedition he had expressed an interest in joining it, the fact that it was an astronomical expedition to a remote site appealing to him. Inquiries made about Van Zadelhoff indicated that he was someone who could be expected to handle the practical aspects of such an expedition well and should be a useful person to have along. The Navy was therefore asked to release Van Zadelhoff for secondment to Leiden Observatory, which they agreed to do, with the result that he came to work there in 1946 in order to get acquainted with the observing principles and instruments involved in the expedition.

The Dutch Army also did its share, chiefly by helping to find equipment from official 'war spoils'. This was the source of the truck, the batteries, the dynamo for re-loading these, even the wood for the crates in which the instruments were shipped. Some of the equipment turned out to be a mixed blessing. The batteries came to be suspected of having come from a submarine that had been sunk; at any rate their performance was felt to indicate a strong probability that they had spent some time at the bottom of the sea. The truck was essential for all sorts of transport jobs, but used petrol at the rate of 1.4 gallons per mile, making it expensive for day-to-day use in picking up stores and provisions and transporting people. It also provided a fine example of Dutch bureaucracy when, some months after the expedition left, the Department of Education ordered the Observatory

To apply without delay the inscription: Departmental Car, in letters 8 $\mathrm{cm}$ high and $1 \mathrm{~cm}$ thick, on the inside of the windshield, at the top of the right-hand side, together with the Departmental Insignia M.K on the lefthand front fender and on the right-hand rear fender ... and advise when such has been carried out. In case of non-compliance the car will be confiscated if found on the road. ${ }^{26}$

It must have been a pleasure to send off a cool answer stating that the car had left the country for Kenya some time ago. ${ }^{27}$

Finally, the army provided fire arms on loan, so when the expedition left they 
were equipped with two rifles and two pistols, with a full complement of triggers and firing pins and bullets, and even bayonets.

The intended expedition was given considerable publicity. It was to be the first Dutch scientific expedition after the war, and there was a great deal of public interest. Letters began to come in from people interested in joining in any capacity whatsoever; the youngest applicant was 16 years old, and he was told kindly but firmly that it would be more useful for him to go to school for a few more years. A surprising number of applicants had been trained as a cook. One applicant had grandiose views of large numbers of expedition members, clashes with the natives, bribery of local officials with Dutch Gin, etc., and offered to organize a large-scale advertising campaign in order to raise several hundred thousand guilders. He was sent a letter saying essentially that he might not have quite the right idea of what the expedition would be like and that in any case Van Herk had been there before and had never needed recourse to bottles of gin. All applicants were told that the amount of funding put strict limits on the size of the expedition and that therefore their offers had to be regretfully declined.

Contacts with Kenya were renewed. Mr Walter, now Group Captain Walter, the meteorologist who had been helpful during the first expedition, again proved helpful. He was instrumental in allotting Crown Land to the expedition, and assisted in contacting local saw mills for the construction of prefabricated houses, and with general advice. The Dutch Consuls in Kenya, J. H. Schmüll and J. M. Donker, gave help and friendship. This time the railways were contacted beforehand, and they promised rebates of $50 \%$ on the freight charges and special fares for the expedition members. Two houses were ordered, to be constructed some $400 \mathrm{~m}$ from the observing site, and to be taken apart and sold at the end of the expedition. They were three-bedroom wooden bungalows. The kitchen would be the servants' domain, and was separate from the house but connected by a covered walkway. At $2850 \mathrm{~m}$ above sea-level, fireplaces were essential, even on the equator. The roofs served also as water collectors, as the expedition was totally dependent on rain water. The new site was within three kilometres of the location of the first expedition, at a place called Timboroa.

In the midst of the preparations a letter arrived from Quito. ${ }^{28}$ The observatory there had had a new director for some years, and he invited the expedition very warmly to come to Quito. Lacking good astronomical instruments and assistants he had used his time in making a thorough study of the climate of Ecuador and thought the previous reports had been less than fair, mostly because observations had been done too close to the slopes of mountains, in places where cloud and fog tend to be persistent. He thought that even as close as $5 \mathrm{~km}$ to Quito there were sites that should be very suitable for astronomical observing, with dry conditions occurring sufficiently regularly in the course of each year. He made the point that everywhere near the Earth's equator climatic conditions should in principle be the same, with variations mostly a matter of the presence of mountains and highlands. Later on during the second expedition someone sighed: "If only we had gone to Quito", and this must have been the letter that gave rise to that remark. However, the organization was too far 
advanced to change, and there still seemed little to choose between the two locations.

In August 1947, the expedition was thought to be sufficiently ready to leave. They embarked on board the Boschfontein on 30 August, and arrived in Mombasa on 2 November. About the first thing they found was that the houses, which were supposed to be ready for them, in fact were not, so the families of Van Herk and Van Zadelhoff had to stay in a hotel while Van Herk, Van Zadelhoff and De Haan lodged with the present incumbents of Canada Farm, the Knake family, and began the construction work for the observing station with the aid of a number of local workmen.

\section{Construction of the Observing Station}

The observatory for the first expedition had consisted of only one hut. This time more was needed. Three telescopes had been brought: the azimuth instrument, a zenith telescope to measure the latitude variation, and a Schmidt camera from Philips together with a searchlight mirror for measuring the zodiacal light. The last programme was one that Van Herk was eager to carry out, and for which the equator is an ideal site. It had proved possible to use some of the money allocated by American funds to buy several of the new types of photomultipliers that had very recently come on the market, and that were ideally suited for measuring the intensity distribution of the zodiacal light at various wavelengths. In addition to the telescope huts, for which the construction problems were much the same as in 1931, protective sheds had to be erected for some auxiliary equipment. The final result was a gaggle of sheds in all sizes, making the station look somewhat like a chicken farm, or possibly like a modern all-wood children's playground (Figure 5).

This assortment of structures had become necessary because of the calibration difficulties. These arose from the fact that the azimuth instrument had been fixed at one zenith angle. It was therefore impossible to use it to observe cycle stars at $45^{\circ} \mathrm{ZA}$ (as described above) but this was corrected for by using a slightly different observing method. It was also impossible to observe directly the azimuth of a mire without putting the mire on a prohibitively high pillar. This last difficulty was solved by installing angled mirrors, and locating two mires at a distance of approximately $60 \mathrm{~m}$ from the azimuth instrument. The mires and mirrors all had to be made as stable as possible, and protected from the weather; they were therefore all built into special sheds, with complicated arrangements of shutters ensuring their accessibility.

A lot of back-breaking work went into making the site accessible. The road to the hill was very bad, especially during the rainy season, when it would consist alternately of slippery red mud and potholes. The potholes had to be filled in with rocks, and the mud kept in check in the same way. This time the instruments were brought up the hill by truck rather than by ox cart. Opinions differ as to whether this constituted an improvement. When the instruments were unpacked it was found that this time practically all of them had suffered considerable damage during shipping: rods were bent or broken off, tubes 


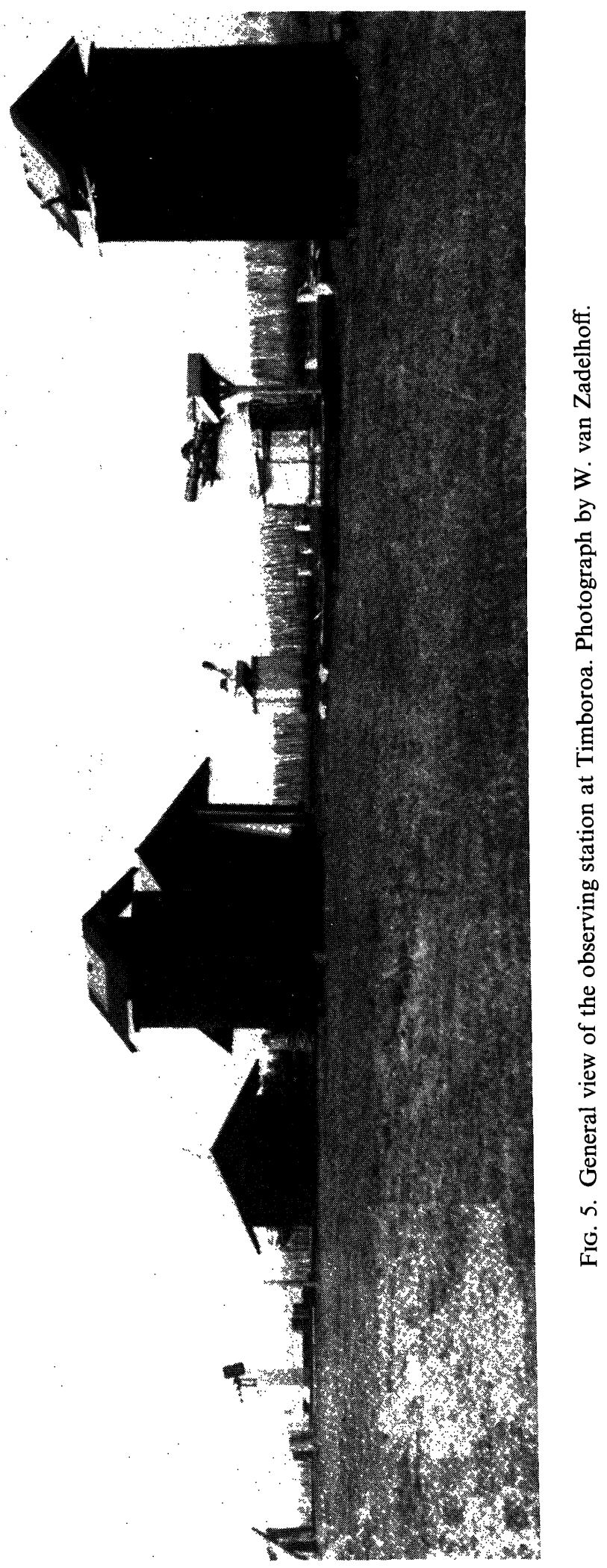


damaged. Fortunately, it proved possible for Van Herk and Van Zadelhoff to repair most of the damage themselves, even though they did considerable improvising: the zenith telescope was held together by bamboo splints for the remainder of its use, as bolts were missing and there were some delays in getting the correct size sent out by Leiden. One job, involving damage to the azimuth instrument, had to be taken to Eldoret, where fortunately the owner of a machine shop proved able to make the repair.

Away from the observatory site a sizeable building was erected to house the truck, as well as a workshop and battery shed, where the batteries were to be reloaded regularly. All over the hilltop an electricity grid was installed and connected to the telescopes and clocks that all had their special requirements for electricity; in addition the mires had very small light bulbs in them, and the observer also needed some light. There were also radios, essential for the time signals. In December the houses were finally ready to be assembled. They were put up in a matter of weeks, but making them liveable took longer: water had to be piped in and, again, electricity installed. An unsuccessful attempt was made to install telephones: the batteries did not have enough capacity. All this work had to be carried out at an altitude of $2850 \mathrm{~m}$ above sea level, in a place where it was fairly warm at midday but where fires were needed in the morning and at night because of the low temperatures and strong winds. The altitude made hard physical labour impossible; it was very difficult to move faster than at a walking pace. Still, steady progress was made.

\section{Living Conditions}

In January 1948, the Van Herk family moved into their house, being the first to do so. They were confronted almost immediately with the local dangers: in early February a prairie fire broke out. The local farmers had the habit of burning off the grass at the end of each summer; with the prevailing strong winds these fires easily got out of hand, and on this occasion they threatened the houses. Fortunately the ground around the houses had just been ploughed in preparation for putting in gardens, and this saved the Van Herks. That evening, the manager of a local saw-mill came up the hill to see exactly where the fire had been and if his woods had been affected, and found to his consternation that there were actually people living there! One result of this experience was that for the rest of their stay the expedition members made a point of keeping the ground around observing station and living quarters well cleared. We shall give below a description by Van Zadelhoff of a later fire.

The Van Zadelhoff family moved in in mid-February. Both families had two school-age children who went to boarding school at Eldoret and in Nairobi and came to Timboroa only during school holidays. Both families had household servants, whose most important duties were to cook, to keep the much-needed fires going and to look after the garden. As the construction period occurred during the first dry season of their stay, there was not very much for the gardener to do at first. Gardens were prepared and seeds put in, but it had to be left at that. They hoped ultimately to grow at least part of their own vegetables 
but for the first few months they were dependent on what was available from local farms and on supplies that had to be ordered at Eldoret from where they would be sent by train to be picked up at the station of Timboroa. The diet was far from ideal. The Van Zadelhoff family had also bought a few chickens for their own supply of eggs, and a donkey, which Van Zadelhoff hoped to be able to convince to carry loads. There was some rainfall, but for the first few months the water situation was precarious. All water had to be brought up by truck, and some holes were dug that were hopefully referred to as wells, but all those ever yielded was about a cupful. At the beginning of the wet season the expedition members noted with relief that now at least they had enough water to rinse clothes properly.

It was fortunate that the construction work could be carried out during the dry season, and even when the rains started they tended to fall at night, so that reasonable progress could be made on the construction. Still, it all took very much longer than had originally been hoped, and by the time De Haan left, in March 1948 (a few months earlier than expected because of personal difficulties), things were not nearly ready. One problem was that Kenya, like the Netherlands, was still suffering from post-war shortages, and permits were required for almost all building materials; this situation also contributed to the delay in the construction of the houses. Another problem was that repairing 'normal' wear and tear took up a great deal more time than had been foreseen; for example, road conditions in Kenya were such that the truck kept having to be repaired, mostly at the garage at Eldoret, where work went slowly and not particularly surely. If at all feasible, repairs were carried out at the site. There were some scares: one night, the Van Zadelhoff family were taking their son to the train, which was due to leave at 3.50 a.m. from Equator; as they were going down the hill the footbrake of the truck failed. Switching off the engine and applying the handbrake did not help sufficiently, so Van Zadelhoff tried to bring the truck to a stop by driving along the verge, hoping the friction would brake the truck, but instead it turned over. They were lucky; other than some skin abrasions there was no personal damage. They heard the train leave in the distance, trudged back up the hill on foot, and went to rescue the truck the next day.

With all these difficulties, the expedition members became very good at improvization. For instance, at one stage there were enough light bulbs but not enough sockets to put them into, so these were improvized from fuse holders, of which they happened to have a good supply. These worked beautifully. Still, in the letters from this period there are frequent requests for bulb sockets, both from Van Herk to Oort and from Oort to various contacts (Jan Schilt and others) in the USA.

Then there was the problem of the local workmen. They were in very short supply, and wages had gone up considerably since the first expedition. A number of them were employed for varying periods of time, with varying degrees of success; sooner or later either their wage demands would increase too much or they would leave on unexpected holidays and not come back. A few were reliable and remained working there for most of the expedition's duration. 
The servants and assistants built their own huts near to the wooden houses: wood skeletons, cane-thatched, with walls of plastered mud. Making the walls and roofs was considered women's work, so some women were hired, and the cane had to be brought in from nearby Lake Nairasha. When some of the huts had to be rebuilt after a bush fire Van Herk put his foot down when it came to hiring women and importing cane, and all of a sudden there was no problem whatsoever with using the local tall grass and doing it themselves.

Thus the expedition gradually settled down. The children went to school regularly, the buildings approached completion, the rainy season started, the vegetables came up (at least the potatoes and cabbages did), and there was plenty of water again, and sometimes too much. The expedition members adapted reasonably well to the high altitude, although possibly some tensions and errors that occurred later can be ascribed at least in part to altitude effects.

Life on the mountain had its dangers other than the altitude, the isolation and the bad roads. Every now and again there would be bush fires, some of which would threaten the camp. There is a journalistic report of one particularly bad fire in one of Van Zadelhoff's articles for the Dutch magazine Elsevier. ${ }^{27}$ On 6 April 1949, a bush fire broke out on the grounds of Canada Farm, some $600 \mathrm{~m}$ east of the observatory. While Van Zadelhoff and the local staff started a counter-fire (keeping it under control with green branches), Van Herk went off to see how bad it was, but had to sprint back, with the fire literally at his heels, a wall of flames raging on a front hundreds of metres wide.

Hurriedly we set the surroundings of the Eastern Mire alight. A wide belt of ground all around it had already been cleared, but the flames were such that they could easily have jumped across to the dry wood. We only just managed to do this before having to fall back; the hard wind made it impossible to remain. The road was no longer an obstacle as sparks and burning branches blew across it ....

After a relatively short time however the fire had passed the Observatory and raced in the direction of the living quarters, so that we had to fall back on them in a great hurry ... the stormy wind and sudden whirlwinds were very dangerous for the many thatched roofs, the garage, and even the bone-dry wooded roofs of the houses ... in the meantime the bamboo grove on the Northern side of the hill had caught fire, where the flames rose tens of metres and there was an enormous crackling of burning bamboo. The noise that makes very strongly reminds one of the wretched war years: heavy machine-gun fire in the distance. It seems the hollow bamboo trunks explode.

At about 2 o'clock flames broke out of the central one of the servants' huts near Van Herk's house. Within ten minutes the large hut was a ruin, and the only thing we could do was keep the other huts as wet as possible. ${ }^{30}$ Because of the high flames one of the trees caught fire too, so that we had to chop off large branches. It must have been an impressive sight, this burning hill. By midday the woods on the southern slopes also burned like torches, and the sky was darkened by the smoke. ... 


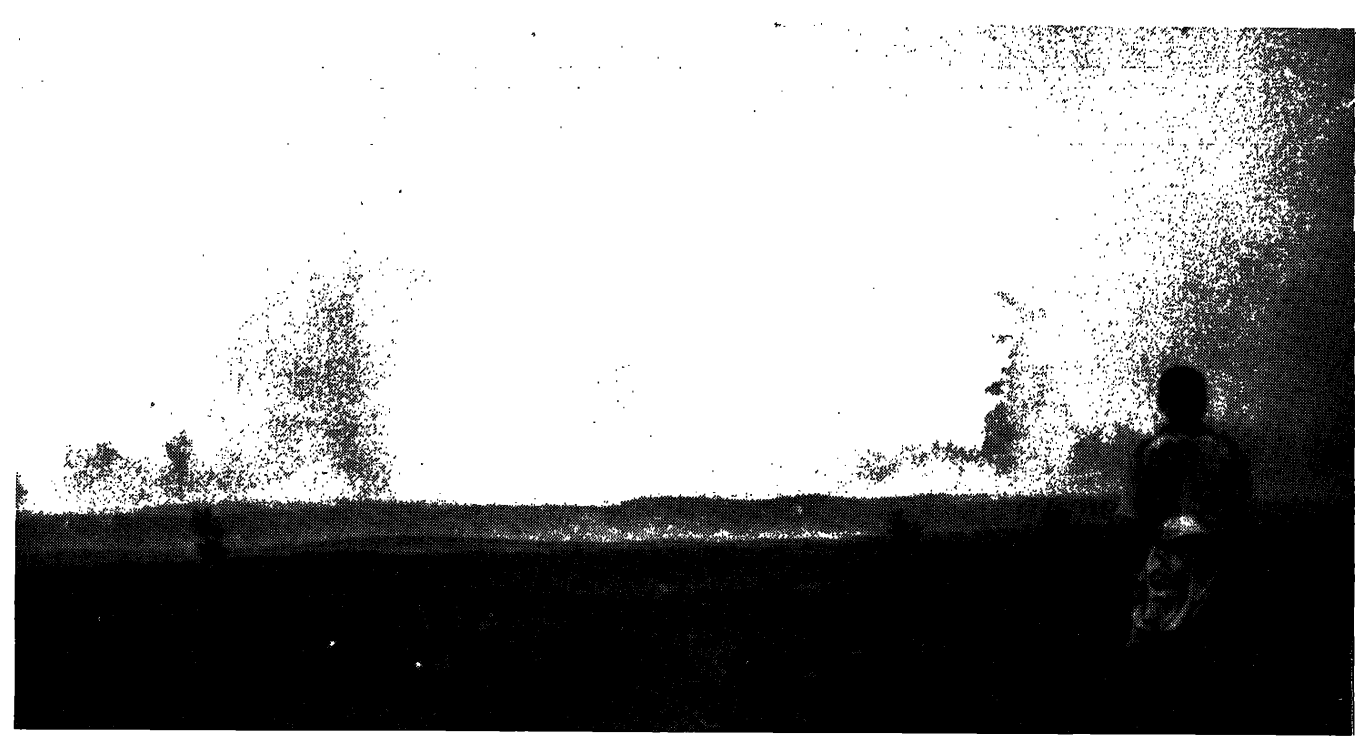

FIG. 6. Prairie fire at Timboroa. Photograph by W. van Zadelhoff.

We had the usual interesting visit from storks, as soon as the fire started ... at least a dozen were stalking along some tens of metres behind the flames, pecking at the various nice fried tidbits that evidently were to be found there ... [Figure 6].

\section{The Observations}

By the time the rainy season started the observing station was not yet ready. Whereas during the first expedition Hins and Van Herk had taken two months from arrival to starting observations, now the scarcity of building materials and of manpower was so great, and besides the size of the second expedition made the organizational work so much more involved, that the first observations were not done until approximately eleven months after arrival, namely on 5/6 October 1948, at the beginning of the second dry season since the arrival of the expedition.

Because considerable changes had been made to the instrument the method of observing had to be different from the previous time. Stars were again observed in cycles in alternating eastern and western observations, within narrow declination intervals symmetric to the equator, but the procedure now was as follows:

The telescope was set at the roughly computed azimuth ... the star images were bisected with a vertical, hand-driven, wire, preferably at least six times in succession, while the time of bisection was recorded with the signal key on the printing chronograph. As we wanted to observe the crowded programme as quickly as possible we tried to keep the interval between stars as short as could be. As a consequence stars were usually observed as soon as they entered the field to enable us to pick up the 
following star sometimes in the second half of its passage through the field. ... The micrometer was read at each bisection. The circle was photographed either before or after the star was observed; occasionally both moments were used as a check on the readings. The level was read also either before or after the star passage .... ${ }^{31}$

In the first expedition, preliminary reductions had been done in Kenya to see if all was going well. This time the films registering the circle readings and the recorder charts were sent to Leiden. It rapidly became clear that the registrations of the circle readings were unsatisfactory: it was almost impossible to measure the readings properly from the photographs.

Steps were taken to remedy this. For the time being readings were also taken by eye. Furthermore, new lenses were provided, and in late 1949 A. Blaauw took these to Kenya to try them out personally. His arrival was very welcome; the small community at the station badly needed reinforcements, and if these took the form of someone already known to them who was also a professional astronomer so much the better. The astronomical help was particularly important. The combination of preparing, carrying out and keeping track of the observations and keeping the station running, and all this at $2850 \mathrm{~m}$, was really too much for two people, only one of whom was a professional astronomer. Blaauw spent about half a year at Timboroa, installing the new lenses, making them operational and helping to get the observations going again. On his return to Leiden he stressed the need for sending out another astronomer.

At around this time Oort also paid a short visit, on his way back to Leiden from South Africa; so that he was able to see at first hand the day-to-day problems with which the expedition had to cope.

There were further observational problems, some of which could be solved, and some not. Comparisons of observations made in the west with those made in the east agreed well for some zones; for others, there were odd discrepancies. One such discrepancy caused Van Herk considerable worry. It showed up with very similar amounts for all four observers (viz. Van Herk, Van Zadelhoff, Blaauw and, eventually, Schmidt). In the end Van Herk concluded that the error must be due to an inaccuracy in the circle. The observations had been done with four different settings of the circle zero, and separate reductions for each circle zero setting gave some evidence that there was in fact such an inaccuracy. Another problem was the possibility that the observations might be affected by lateral refraction, and the impossibility of determining by how much this might be the case. For instance, the discrepancy mentioned above could also have been due to the presence of a 'fold' in the terrain at a distance of about $300 \mathrm{~m}$; there were other discrepancies for which it was possible to find corresponding deviations in the terrain, but it was impossible to determine just how much lateral refraction these would cause; Van Herk calculated upper limits to the size of the declination error due to this effect from theoretical considerations. He obtained values varying smoothly from $+0^{\prime \prime} .17$ for $\delta=-50^{\circ}$ to $-0^{\prime \prime} .17$ for $\delta=+50^{\circ}$ and decided that the values were too uncertain to correct for. In the final results there is certainly nothing corresponding to a trend of this kind. 
These are just some instances of the problems involved in obtaining and reducing the observations; the entire reduction procedure with its checks of possible sources of errors is described in detail in Van Herk's article in Annals of Leiden Observatory. ${ }^{32}$

In addition to the azimuth instrument, the zenith telescope was also used extensively in determining the latitude variation of Timboroa, at least during the first three years, until one day it was irreparably damaged when, after Van Zadelhoff had made an error in securing the telescope, a gust of wind slammed the hut into the telescope. The zodiacal light observations never were carried out, to the regret of Van Herk but also of Van Zadelhoff, who had always expressed a special interest in them; the zodiacal light observations had been given a fairly low priority, and it proved difficult enough to finish the azimuth programme in anything near the allotted time. The expedition had been planned to last three years; at the time of the accident to the zenith telescope it was just becoming clear that it would have to be extended for at least one more year. Van Zadelhoff now became restive; he had been seconded in 1946 and felt that four years of secondment was quite long enough. His children were growing up and would be needing secondary schooling soon, the contract for sub-letting his house was running out, and he started worrying that an extension would damage his career prospects in the Navy. Also, personal relations on the mountain, always vulnerable because of the tensions inherent in the demanding work, with its extremely irregular working hours, and in the isolation, had deteriorated after the expedition had been joined by a young physicist from Amsterdam, come out to carry out cosmic ray experiments, who may have been severely affected by the altitude, and in any case did not fit in at all well. Relations between this person and Van Zadelhoff rapidly deteriorated into animosity, and at one stage they almost came to blows. There was a general relief when this man left and was replaced by another physicist, a Mr Strackee, who proved friendly and helpful, and was a decided asset to the expedition.

Anyway, Van Zadelhoff requested to be relieved as of mid-1950. It was felt to be a very reasonable request, and promptly granted, but it was also obvious that Van Herk could not possibly carry on on his own. The programme was far from finished; its completion was going to take at least another year. Fortunately there now was a good prospect of replacing Van Zadelhoff by a professional (or, rather, professional-to-be) astronomer, as Leiden now had a promising young student, Maarten Schmidt, who was doing his doctoral studies, and who was willing to go to Kenya for one year. Van Zadelhoff left in August 1950, and Schmidt arrived around October, at the beginning of the last dry season the expedition was to spend there. It rapidly became clear that he was a good choice; in the end he was responsible for some $24 \%$ of all azimuth observations (Blaauw for $9 \%$, Van Zadelhoff for $13 \%$, Van Herk for $54 \%$; note that Van Zadelhoff did quite a large share of the zenith telescope observations). 


\section{The Winding Up of the Expedition}

By late 1949 the expedition had gotten into its stride, with observations coming in regularly. However, as mentioned above, it was already becoming clear that the goal of the expedition could not possibly be reached by mid-1950, and extending it implied unavoidable extra costs. The expedition, though run on a shoestring budget from first to last, had already turned out to be more expensive than expected: Blaauw's passage had had to be paid for, and now there was the return journey of Van Zadelhoff and his family, and the additional expenses caused by sending out Schmidt. Also it had become clear that having only the one truck for transport made things very difficult. There had been one occasion when it had had to go to the garage for two weeks for repairs. Fortunately it had been possible to hire a truck from a farmer Austin who lived relatively nearby, but these things made the expedition vulnerable. Running the truck was in any case very expensive and it was felt that buying a sturdy, used car would be a good investment. Fortunately they now had the local contacts to ensure that they would be able to get hold of a good car; Mr "Pop" Binks, an amateur astronomer from Nairobi who had become friends with the members of the expedition, helped them find a car that could be expected to serve them for the remainder of their stay as well as local conditions permitted. Not without some further mishaps, though; the worst one was when Schmidt, driving the car downhill, hit a rock or branch or something lying in the road, causing it to overturn and breaking Schmidt's leg. A first draft (author unknown) of the description of the accident for the insurance company goes as follows: the car "ran up the bank and turned over onto the offside, trapping Mr. Schmidt's right foot, which was through the driver's window, for reasons which escape me". Schmidt spent two weeks in hospital and was unable to work full-time for some months.

To return to the financial side of the extension: the expedition had already been greatly helped by financial support for ZWO, the new Netherlands Organization for the Advancement of Pure Research, which was established formally in 1950 but which had in fact already been operational since 1947. It contributed heavily to the ever-mounting costs of the expedition: whereas these had originally been estimated at approximately $f 70,000$, by 1949 they were set at $f 113,000$ and still rising. At the end of 1950 another application was submitted to ZWO, this time for $f 18,000$ with the total cost of the expedition set at $f 133,000$ and a request for an extension in time to the end of 1951. But ZWO decided to call it a day. They agreed to one final grant, with the proviso that any money left over from the sale of houses, cars, etc. was to be paid back to them. The organizers had to accept these conditions.

In October 1951, the observing station was dismantled, the cars, houses, batteries, etc., were sold, and the expedition members came back to the Netherlands. The Van Herks had been away for more than four years, enduring considerable hardship. The azimuth instrument also was shipped back to the Netherlands, put in one of the small domes of Leiden Observatory, and there it still stands. 


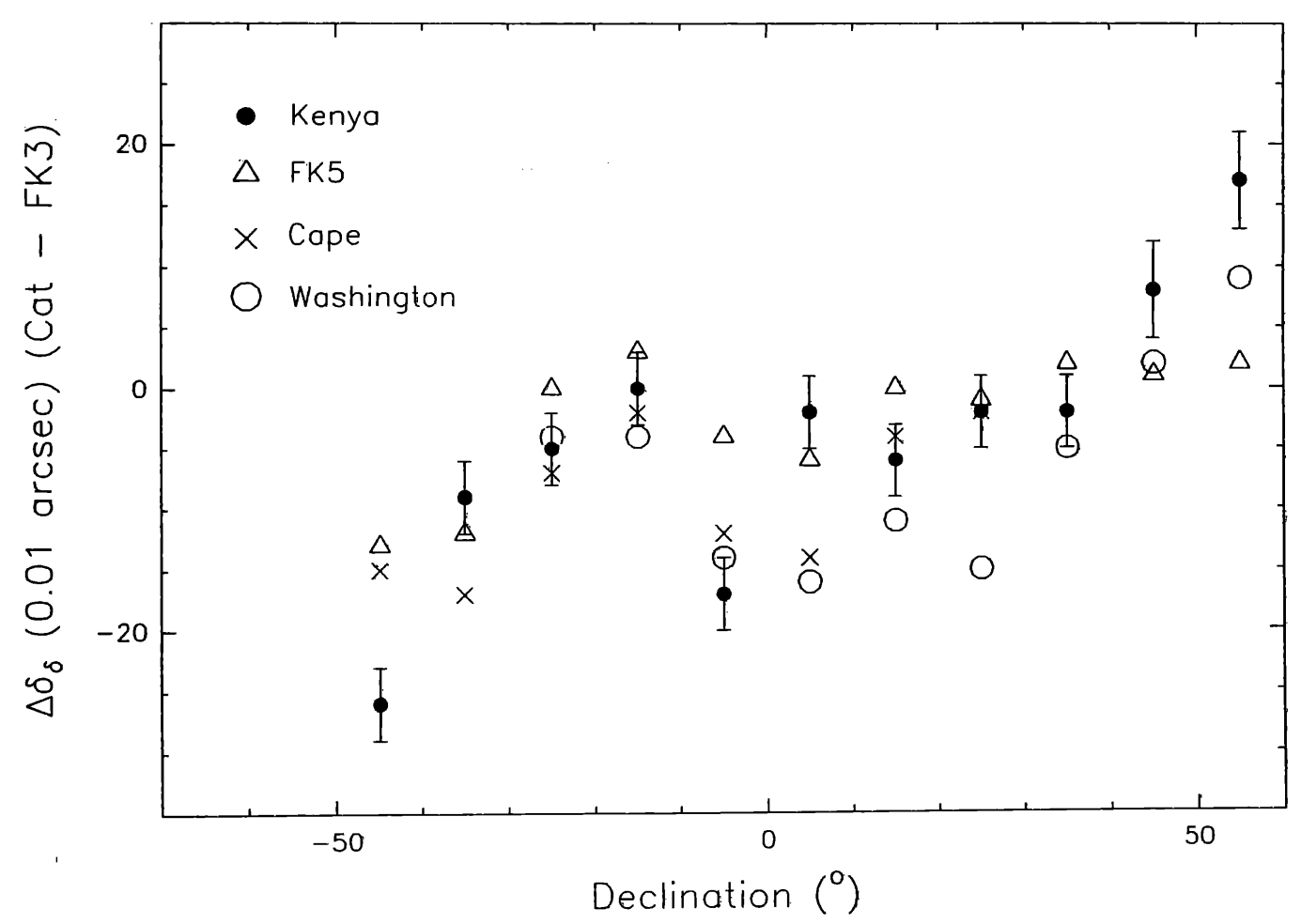

FIG. 7. Corrections to be applied to the declinations listed in the various fundamental catalogues, per declination zone. The catalogues used for comparison are indicated in the figure. The values of the FK5 comparison are courtesy of A. Blaauw.

\section{Results}

The results of the observations were published in a very thorough paper in the Annals of Leiden Observatory, ${ }^{33}$ in which Van Herk tries to account for all errors that might have affected the observations. Some it was not possible to derive; there were clock errors that were hard to trace back, and, as mentioned above, lateral refraction could have been a problem. However, David Evans's statement ${ }^{34}$ in his book Under Capricorn that the results were unreliable because they were badly affected by lateral refraction is almost certainly incorrect. Taking everything together, the impact of the results must be seen as disappointing. A general tendency seems to have been to assume that the corrections the results gave to existing catalogues must have reflected errors in the observations rather than in the catalogues, even though the reason for the expedition was that some corrections could not be determined in the normal way with meridian instruments. Some impression of the reliability may be obtained from Veröffentlichungen des Astronomischen Rechen-Instituts Heidelberg, xx (1968), where the results are included in a list of astrometric catalogues; comparison shows that for northern declinations $\left(\delta>+20^{\circ}\right.$ or so) agreement with northern surveys is excellent, and for southern declinations $\left(\delta<-20^{\circ}\right)$ the agreement with the Cape observations is very good. This should mean that as there is good agreement in just those zones where meridian instruments are 
most reliable because refraction and flexure are negligible, the principle is correct and that therefore the values for intermediate declination zones are intrinsically more reliable than meridian observations at northern and southern observatories. This is confirmed by the first results from the FK5, which A. Blaauw summarized for purposes of comparison and made available for this article (the results are shown in Figure 7). For a definite judgement we may have to await results from HIPPARCOS, but my impression is that the method when applied properly and with enough observations available is at least as accurate as any other.

\section{ACKNOWLEDGEMENTS}

I should like to acknowledge the extensive help that was given by $\operatorname{Dr} G$. van Herk in discussing the results of both Kenya expeditions; his reminiscences were invaluable in placing the expeditions in a proper perspective. I am grateful to Professor A. Blaauw for suggesting this subject, for taking a vivid interest in the course of the work, and for providing photographs and the FK5 comparison. I thank Professor W. B. Burton for his critical reading of the manuscript. The Oort Archive Project, an initiative undertaken by Professor Burton, is supported by the Netherlands Organisation for the Advancement of Research (NWO).

\section{REFERENCES}

Three major sources of material have been used for the present article, namely: (1) the correspondence between C. Sanders and E. van de Sande Bakhuysen and between C. Sanders and W. de Sitter, from the archives of Leiden Observatory, (2) the files on the Kenya expeditions archived with the Oort Papers, at the Leiden University Library, department of Western Manuscripts, and (3) an interview with G. van Herk (who participated in both expeditions), which has been recorded on tape. The first source comprises boxes 4 (files 8-16), 20 (file 17) and 122A of the Observatory archives, the second source comprises boxes of which the number starts with 3.7 within the Oort Papers. Within the references these sources are referred to as $\mathrm{S}+$ number, $\mathrm{O}+$ number and " $\mathrm{G}$. van Herk, private communication" respectively.

1. J. C. Kapteyn, “Ueber eine Methode die Polhöhe zu bestimmen”, Copernicus, iii (1883), 147-82.

2. C. Sanders to E. van de Sande Bakhuyzen, 18 January 1917 (in English), S4.8.

3. C. Sanders, "Determination of latitude and declinations", The observatory, xl (1917), 271-3.

4. Ibid., 273.

5. W. de Sitter and J. H. Oort, "A provisional scheme for the determination of fundamental declinations from azimuth observations", Bulletin of the Astronomical Institutes of the Netherlands, iii (1925), 1-6.

6. C. Sanders and J. H. Oort, "A discussion of the determination of declinations from azimuth measures made near the equator", ibid., ii (1925), 201-8.

7. W. de Sitter to the Director of Quito Observatory, G. Tufino, 26 June 1929 (in English), O3.7.1931(b).

8. Letter from G. Perrier, previous director of Quito Observatory, 30 January 1930 (in English), O3.7.1931(b).

9. As repeatedly reported by De Sitter in letters to C. H. Hins, see O3.7.1931(a).

10. Letter from C. H. Hins to W. de Sitter, late 1931 (original in Dutch), O3.7.1931(a).

11. Records of C. H. Hins, 22 October 1931 (original in Dutch), O3.7.1931(a).

12. Letter, C. H. Hins to J. H. Oort, 1 January 1932 (original in Dutch), O3.7.1931(a).

13. Hins does not seem to have considered at this stage that the deviation might reflect a local 
deflection of the vertical, as might well have been the case (G. van Herk, private communication).

14. Letter, C. H. Hins to W. de Sitter, 22 March 1932 (original in Dutch), O3.7.1931(a).

15. Quoted by De Sitter in a letter to Hins, 22 August 1932 (original in Dutch), O3.7.1931(a).

16. Quoted by De Sitter in a letter to Hins, 25 June 1932 (original in Dutch), O3.7.1931(a).

17. Letter, C. Sanders to E. van de Sande Bakhuyzen, 27 May 1918 (in English), S122.

18. Letter from C. H. Hins to W. de Sitter, early May 1932 (original in Dutch), O3.7.1931(a).

19. Letter from C. H. Hins to W. de Sitter, 27 October 1932 (original in Dutch), O3.7.1931(a).

20. This was an optimistic estimate. Temperatures actually did fall to near the freezing point (G. van Herk, private communication).

21. Van Herk tells of having to avoid a herd of wild boars on another occasion when going to the observing hut on foot (G. van Herk, private communication).

22. Hins's records, 22 October 1931 (original in Dutch), O3.7.1931(a).

23. Letter from C. H. Hins to W. de Sitter, 20 February 1933 (original in Dutch), O3.7.1931(a).

24. C. H. Hins and G. van Herk, "A catalogue of fundamental declinations derived from azimuth observations at a station on the Earth's equator". Annalen van de Sterrewacht te Leiden, xviii/1 (1938).

25. Minute of letter from J. H. Oort to P. J. van Rhijn, 29 January 1943 (original in Dutch), O2.2.1944(d).

26. Letter from Department of Education to Observatory, Leiden, 25 October 1947 (original in Dutch), O3.7.1946(g).

27. Answer to above, 31 October 1947 (original in Dutch), O3.7.1946(g).

28. Letter from J. Odermatt to J. H. Oort, 30 December 1946 (in English), O3.7.1946(g).

29. Article submitted to Elsevier's Weekblad by W. van Zadelhoff in 1949, O3.7.1948.

30. According to Van Herk this cannot have been very wet in view of the usual shortage of water (G. van Herk, private communication).

31. G. van Herk, "Absolute declinations of 1493 stars from azimuth observations". Annals of Leiden Observatory, xviii/5 (1957), 11.

32. Ibid., passim.

33. Ibid.

34. David S. Evans, Under Capricorn (Bristol, 1988), 160. 